\title{
Recent Progress in the Management of Pulmonary Hypertension
}

\author{
Yoshihiro Fukumoto, MD, PhD; Hiroaki Shimokawa, MD, PhD
}

\begin{abstract}
Pulmonary hypertension $(\mathrm{PH})$ is a fatal disease caused by small pulmonary artery obstruction from vascular proliferation and remodeling. $\mathrm{PH}$ is characterized by elevated pulmonary arterial pressure and increased pulmonary vascular resistance, frequently leading to right-sided heart failure and death. The classification of $\mathrm{PH}$ has been recently updated to include 5 major categories of the disorder, are as: Group 1, pulmonary arterial hypertension (PAH); Group 2, PH due to left heart disease; Group 3, PH due to lung diseases and/or hypoxia; Group 4, chronic thromboembolic PH (CTEPH); and Group 5, others. Recently, significant progress has been made in the understanding of the pathophysiology, diagnosis and treatment of $\mathrm{PH}$. Regarding the pathophysiology of the disorder, direct evidence for Rho-kinase activation in the pulmonary artery from PAH patients has been provided. Regarding diagnosis, optical coherence tomography is useful as a new differential diagnostic tool for distal type CTEPH vs. PAH. Regarding treatment, in addition to the conventional therapy, several new drugs are under clinical trial, including fasudil (a Rho-kinase inhibitor), riosiguat (a soluble guanylate cyclase activator), and imatinib (a tyrosine kinase inhibitor). In addition, pulmonary angioplasty and intensive immunosuppressive therapy may be effective for CTEPH and connective tissue disease-associated PAH, respectively. We briefly review the recent progress in the management of $\mathrm{PH} . \quad$ (Circ J 2011; 75: 1801-1810)
\end{abstract}

Key Words: Pulmonary artery; Pulmonary circulation; Pulmonary hypertension; Heart failure

$\mathbf{P}$ ulmonary hypertension $(\mathrm{PH})$, defined as a mean pulmonary arterial pressure $(\mathrm{PAP}) \geq 25 \mathrm{mmHg}$ at rest as assessed by right heart catheterization, ${ }^{1-3}$ is a fatal disease caused by small pulmonary artery obstruction by vascular proliferation and remodeling. ${ }^{4} \mathrm{PH}$ is characterized by elevated PAP and increased pulmonary vascular resistance (PVR), frequently leading to right-sided heart failure (HF) and death. ${ }^{4-6}$

The classification of $\mathrm{PH}$ has been recently updated ${ }^{2}$ to include 5 major categories of the disorder (Figure 1, Table 1). Group 1, pulmonary arterial hypertension (PAH), is a clinical condition defined as mean PAP $\geq 25 \mathrm{mmHg}$ and pulmonary capillary wedge pressure (PCWP) $\leq 15 \mathrm{mmHg}$, which is characterized by the presence of pre-capillary $\mathrm{PH}$ in the absence of other causes of pre-capillary $\mathrm{PH}$, such as $\mathrm{PH}$ because of lung diseases, chronic thromboembolic $\mathrm{PH}(\mathrm{CTEPH})$ or other rare diseases (Figure 1, Table 1).,3 Pulmonary veno-occlusive diseases (PVOD) and/or pulmonary capillary hemangiomatosis (Group 1') should be a distinct category but are not completely separated from PAH because they share similar characteristics with idiopathic PAH (IPAH) but also demonstrate some differences. ${ }^{2,3}$ Group 2, PH caused by left heart disease, is characterized by the passive backward transmission of the pressure elevation (post-capillary $\mathrm{PH}$ ). ${ }^{3}$ There are 2 types of post-capillary $\mathrm{PH}$ : the normal transpulmonary pressure gradient (TPG, determined as mean PAP minus mean PCWP) and PVR, which is defined as the passive postcapillary $\mathrm{PH}$; the other is elevated TPG and PVR, the reactive post-capillary $\mathrm{PH}$ ("out of proportion" $\mathrm{PH}$ ) (Figure 1, Table 2). ${ }^{3}$ Group 3, PH due to lung diseases and/or hypoxia, is caused by hypoxic vasoconstriction as a result of lung diseases, in which PH is generally modest (mean PAP 25$35 \mathrm{mmHg})^{2,3}$ Group 4, CTEPH is caused by chronic and mechanical obstruction of central and/or distal pulmonary arteries by thromboembolic masses (Figure 1, Table 1).2,3,7 Group 5 consists of several remaining forms of $\mathrm{PH}$, for which the etiology is unclear and may be multifactorial (Figure 1, Table 1). ${ }^{2,3}$

We briefly review the recent progress in the management of $\mathrm{PH}$, in terms of pathophysiology, diagnosis and treatment.

\section{New Insights Into the Pathophysiology of PH}

The pathological changes of the pulmonary arteries in $\mathrm{PH}$ include endothelial injury, proliferation and hypercontraction of vascular smooth muscle cells (VSMC) and migration of inflammatory cells (Figure 2).,4,8

PAH and Rho-Kinase Pathway

In the 1990s, Rho-kinase/ROK/ROCK was identified as an

Received May 30, 2011; accepted June 8, 2011; released online July 11, 2011

Department of Cardiovascular Medicine, Tohoku University Graduate School of Medicine, Sendai, Japan

The Guest Editor for this article was Masaaki Ito, MD.

Mailing address: Yoshihiro Fukumoto, MD, PhD, Department of Cardiovascular Medicine, Tohoku University Graduate School of

Medicine, 1-1 Seiryo-machi, Aoba-ku, Sendai 980-8574, Japan. E-mail: fukumoto@cardio.med.tohoku.ac.jp

ISSN-1346-9843 doi:10.1253/circj.CJ-11-0567

All rights are reserved to the Japanese Circulation Society. For permissions, please e-mail: cj@j-circ.or.jp 
Table 1. Clinical Classification of Pulmonary Hypertension (Dana Point, 2008)

Group 1: PAH (Idiopathic PAH, Heritable PAH, Drug and toxin-induced)

Associated with connective tissue disease, HIV, portopulmonary hypertension, schistosomiasis, and chronic hemolytic anemia, etc.

Group 1': PVOD and/or PCH

Group 2: Pulmonary hypertension due to left heart disease

Including systolic and diastolic dysfunction, mitral or aortic valvular disease.

Group 3: Pulmonary hypertension secondary to lung diseases and/or hypoxia

Group 4: CTEPH

Group 5: Other

Including hematologic disorders, sarcoidosis, pulmonary Langerhans cell histiocytosis, metabolic disorders, etc.

Modified from Simonneau et al ${ }^{2}$ with permission.

$\mathrm{PAH}$, pulmonary arterial hypertension; $\mathrm{PVOD}$, pulmonary veno-occlusive disease; $\mathrm{PCH}$, pulmonary capillary hemangiomatosis; CTEPH, chronic thromboembolic pulmonary hypertension.

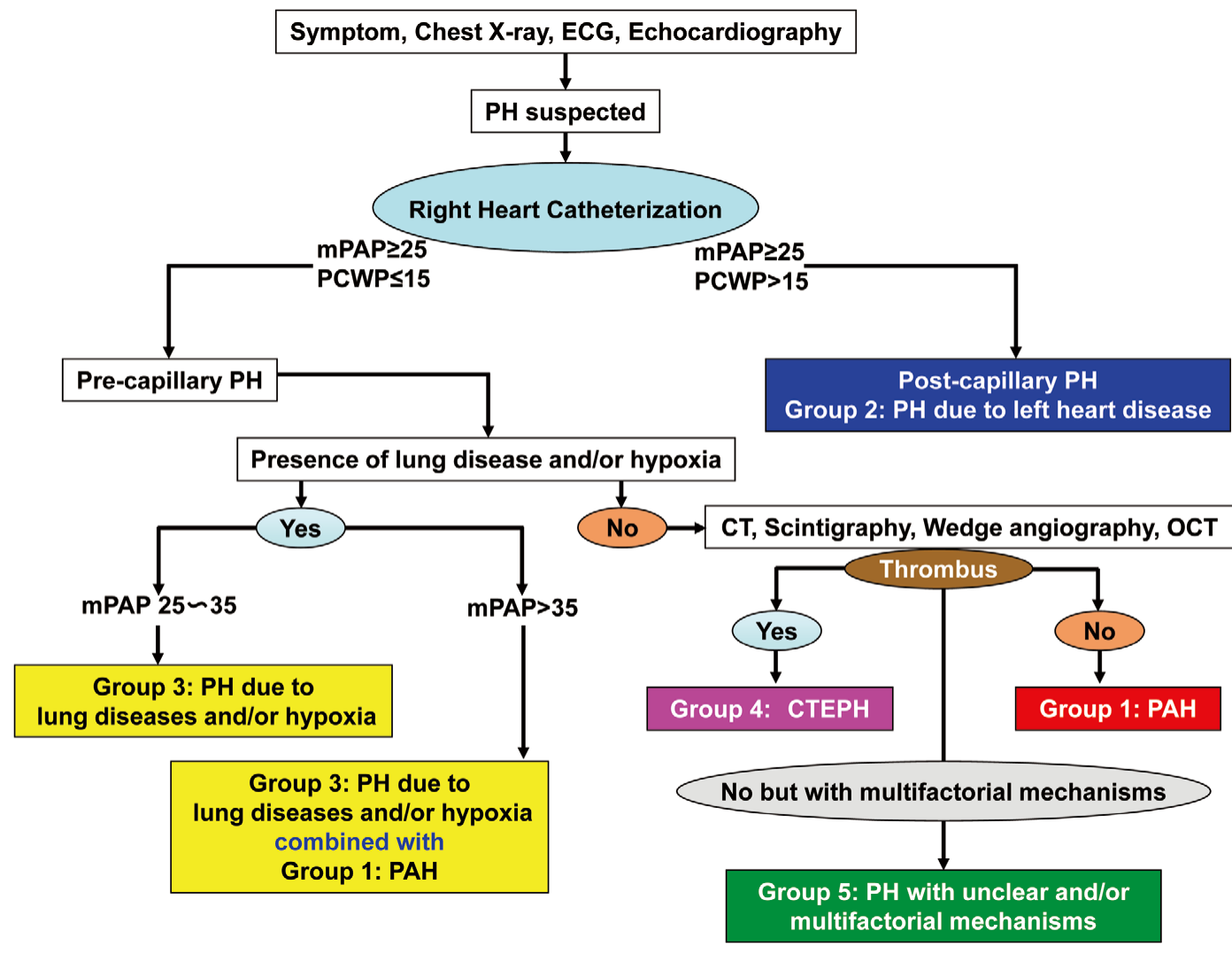

Figure 1. Diagnosis and classification of pulmonary hypertension. CT, computed tomography; CTEPH, chronic thromboembolic pulmonary hypertension; ECG, electrocardiogram; mPAP, mean pulmonary arterial pressure; OCT, optical coherence tomography; PAH, pulmonary arterial hypertension; PCWP, pulmonary capillary wedge pressure; $\mathrm{PH}$, pulmonary hypertension.

Table 2. Definition and Classification of Post-Capillary
Pulmonary Hypertension
Mean PAP $\geq 25 \mathrm{mmHg}$
PCWP $>15 \mathrm{mmHg}$
-Passive TPG $\leq 12 \mathrm{mmHg}$
-Reactive ("out of proportion") TPG $>12 \mathrm{mmHg}$

(Modified from Galie et $\mathrm{al}^{3}$ with permission.)

PAP, pulmonary arterial pressure; PCWP, pulmonary capillary wedge pressure; TPG, transpulmonary pressure gradient defined as mean PAP minus mean PCWP. effector of the small GTP-binding protein Rho, ${ }^{9,10}$ which plays an important role in various cellular functions, including smooth muscle contraction, actin cytoskeleton organization, cell adhesion and motility, cytokinesis, and gene expressions. ${ }^{11-13}$ The Rho/Rho-kinase pathway has recently attracted much attention in the cardiovascular research field for several reasons (Figure 2). First, the Rho/Rho-kinase pathway plays an important role in various cellular functions that are involved in the pathogenesis of a variety of cardiovascular diseases. ${ }^{12,14}$ Second, this intracellular signaling pathway is substantially involved in the effects of many vasoactive sub- 


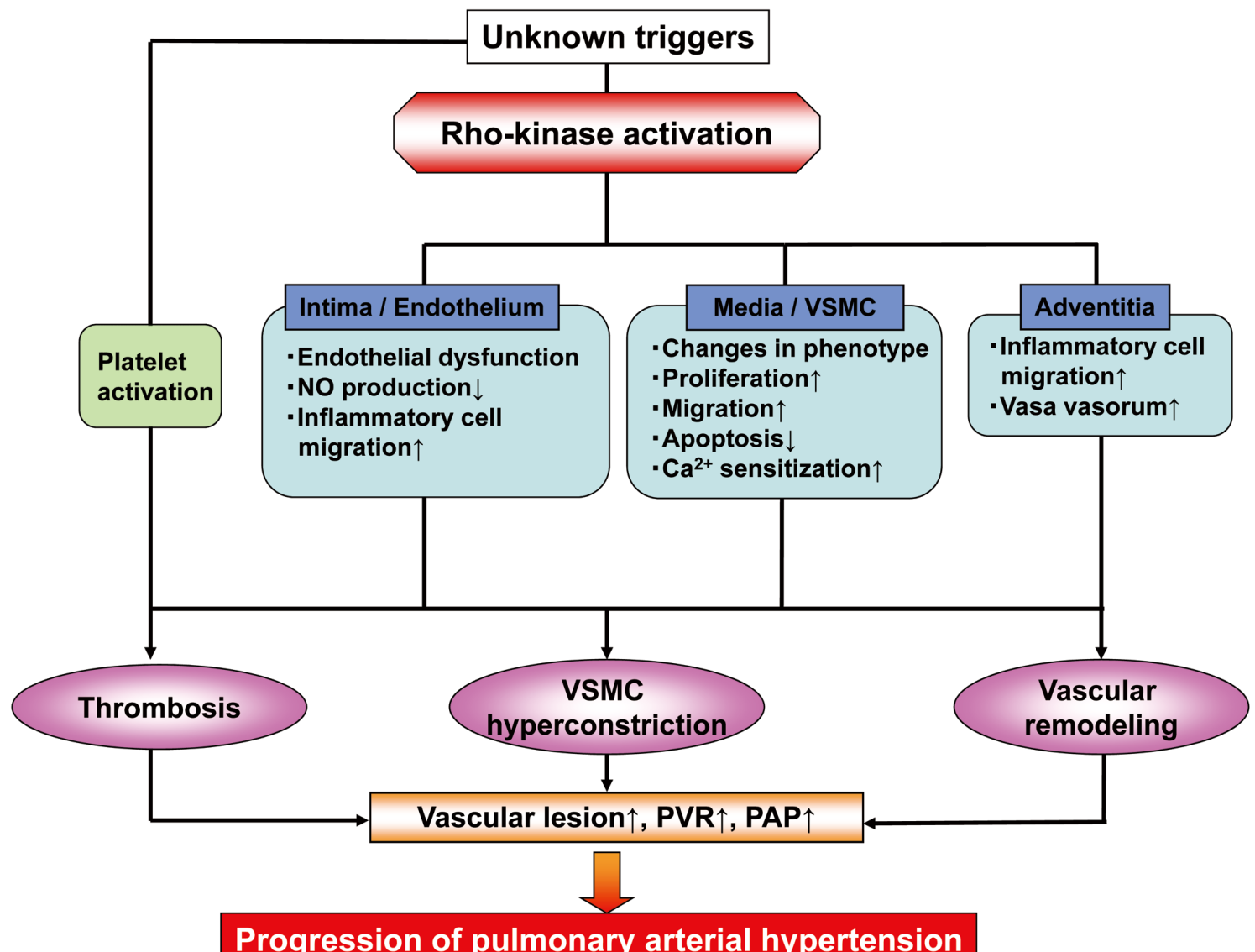

Figure 2. Roles of Rho-kinase in the pathogenesis of pulmonary hypertension. Rho-kinase activation has been confirmed to be substantially involved in the pathological changes of the pulmonary arteries. NO, nitric oxide; PAP, pulmonary arterial pressure; PVR, pulmonary vascular resistance; VSMC, vascular smooth muscle cell.

stances that are implicated in the pathogenesis of cardiovascular diseases. ${ }^{12,14}$ Third, the so-called pleiotropic effects of statins, especially those of high doses of statins, may be mediated, at least in part, by their inhibitory effects on Rho, with a resultant inhibition of Rho-kinase. ${ }^{12,14}$ Fourth, the important roles of the Rho-kinase pathway have been recently demonstrated in the pathogenesis of PAH (Figure 2). ${ }^{5,15-19}$

Rho-kinase suppresses myosin phosphatase activity by phosphorylating the myosin-binding subunit of the enzyme, thus augmenting VSMC contraction at a given intracellular calcium concentration. ${ }^{20,21}$ VSMC hypercontraction mediated by activated Rho-kinase plays a key role not only in coronary artery spasm but also in PAH. ${ }^{5,15,17,22-24}$ Rho-kinase inhibition may be preferable to calcium-channel blockers because of its selective spasmolytic effect on vascular hyperconstrictive segments. ${ }^{5,15,22}$

Rho-Kinase and Inflammation A number of studies have suggested that inflammation may be involved in the pathogenesis of PAH. ${ }^{5,25}$ Some patients with idiopathic PAH have immunological disturbances (eg, circulating auto-antibodies, such as antinuclear antibodies) and elevated circulating levels of pro-inflammatory cytokines (eg, interleukin-1 and -6). ${ }^{25}$ It has been demonstrated that Rho-kinase is upregulated by inflammatory stimuli $12,26,27$ and that Rho-kinase inhibition increases endothelial nitric oxide synthase (eNOS) expression and inhibits inflammatory cell migration and angiotensin IIinduced up-regulation of monocyte chemoattractant protein-1 and plasminogen activator inhibitor- 1 in vivo or in vitro, ${ }^{15}$ in which the Rho-kinase pathway may play an important role in the development of PAH.

Rho-Kinase and PAH Indeed, it has been demonstrated that long-term inhibition of Rho-kinase ameliorates monocrotaline (MCT)-induced PAH and hypoxia-induced PAH in animal models. ${ }^{5,16,18,28}$ In those studies, Rho-kinase activity in the pulmonary arteries was enhanced, irrespective of the different etiologies, and long-term treatment with Rho-kinase inhibitors ameliorated endothelial dysfunction and suppressed hypercontraction and proliferation of VSMC and migration of inflammatory cells. ${ }^{16,18,28}$ In clinical studies, it also has been demonstrated that a Rho-kinase inhibitor, fasudil, acutely improves pulmonary hemodynamics in patients with PAH. ${ }^{17,24,29}$

Enhanced Rho-Kinase Expression and Activity in Patients With PAH Recently, direct evidence for Rho-kinase activation has been demonstrated in patients with $\mathrm{PAH},{ }^{19}$ where Rho-kinase activity is enhanced in circulating neutrophils and the pulmonary arteries from patients with $\mathrm{PAH}$, resulting in hypercontraction of the artery (Figure 3). These findings support the previous findings in animal models of PAH and during right-heart cardiac catheterization in patients with 


\section{Normal PAH}

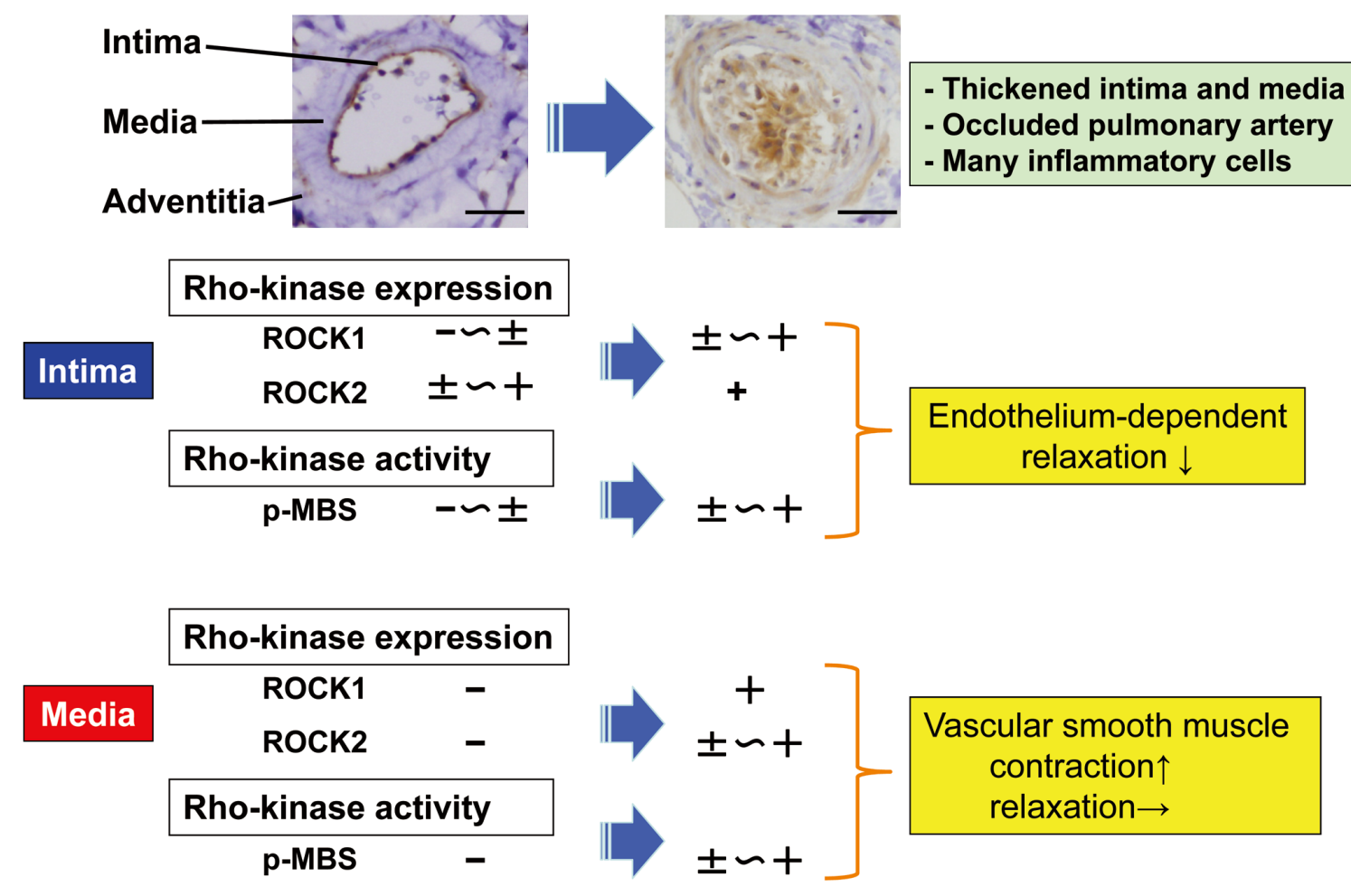

Figure 3. Enhanced Rho-kinase expression and activity of pulmonary arteries from patients with pulmonary arterial hypertension (PAH). Immunohistological findings of Rho-kinase expression (both isoforms, ROCK 1 and 2) and activity in the pulmonary arteries from PAH patients. Activated Rho-kinase expression and activity impairs endothelium-dependent relaxation and enhances vascular smooth muscle contraction. Scale bar, $50 \mu \mathrm{m}$. (Summary of the results of Do.e $Z$ et al. ${ }^{19}$ )

PAH. ${ }^{12,16-18,24,28,29}$ Thus, increased PVR may be caused, at least in part, by the activated Rho-kinase pathway. ${ }^{19}$ In addition, in patients with $\mathrm{PAH}$, eNOS expression is reduced and pulmonary VSMC are hyper-reactive. ${ }^{19,30,31}$ Indeed, activated Rho-kinase causes several important abnormalities, including eNOS downregulation in endothelial cells, VSMC hypercontraction through inhibition of myosin phosphatase, VSMC proliferation and migration, and inhibition of VSMC apoptosis (Figure 2). ${ }^{12,15,27,32,33}$ Also, there is direct evidence that endothelial vasodilator function is impaired and VSMC contraction enhanced in pulmonary arteries from patients with PAH (Figure 3). ${ }^{19}$ These findings are consistent with previous studies using MCT-induced $\mathrm{PH}$ in rats and hypoxiainduced $\mathrm{PH}$ in mice, and previous clinical studies of PAH patients. ${ }^{16-18,24,28,29}$ Furthermore, the inhibition of Rho-kinase abolishes VSMC hypercontraction of pulmonary arteries from IPAH patients, ${ }^{19}$ which is also consistent with a previous clinical study that showed acute inhibition of Rho-kinase improved pulmonary hemodynamics in PAH patients. ${ }^{17,24,29}$ However, it still remains to be examined whether these functional abnormalities of the pulmonary arteries in patients with PAH can be ameliorated by long-term treatment with a Rho-kinase inhibitor. For this purpose, the effects of a long-acting oral form of fasudil in PAH patients are being examined in a clinical trial.

\section{Post-Capillary PH (Left Heart Disease)}

Left heart disease, including systolic and/or diastolic left ven- tricular (LV) dysfunction, is one of the most common causes of $\mathrm{PH}^{34}$ There are 2 types of post-capillary $\mathrm{PH}$, passive and reactive types, which are defined as transpulmonary pressure gradient (defined as mean PAP minus mean PCWP) less than or greater than $12 \mathrm{mmHg}$, respectively (Table 2). Reactive post-capillary $\mathrm{PH}$ is considered to be caused by increased vasomotor tone of the pulmonary arteries and/or structural obstructive remodeling of the pulmonary resistance vessels. ${ }^{3,35}$ Patients with post-capillary reactive $\mathrm{PH}$ are usually female, have valvular heart disease and elevated PAP with left heart disease. ${ }^{36}$ It has been reported that patients with this disorder have an increased risk of postoperative right ventricular $\mathrm{HF}$ after heart transplantation. ${ }^{37}$ However, the detailed mechanisms of the condition remain to be elucidated.

\section{Chronic Thromboembolic PH}

CTEPH is caused by mechanical obstruction of pulmonary arteries by residual pulmonary thromboembolism (PTE) or in situ thrombosis, ${ }^{3}$ which may be initiated or aggravated by abnormalities in the clotting cascade, endothelial cells or platelets. ${ }^{3,38}$ Although inflammatory infiltrates are commonly detected in pulmonary endarterectomy specimens, it remains unknown whether thrombosis or platelet dysfunction is the cause or consequence of the disorder. ${ }^{3}$ It has been reported that the plasma levels of factor VIII are elevated in patients with CTEPH. ${ }^{39}$ Although Rho-kinase is activated in patients 
Control

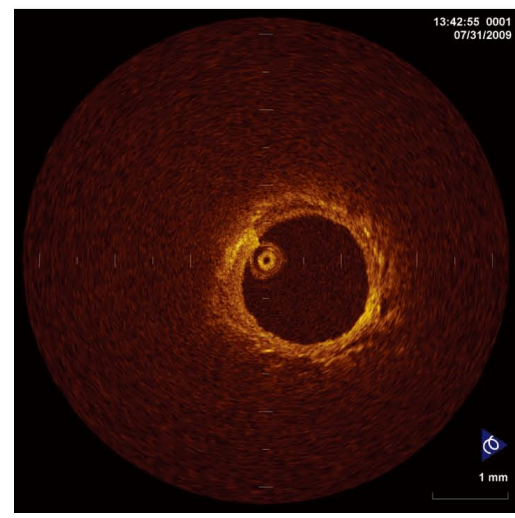

PAH

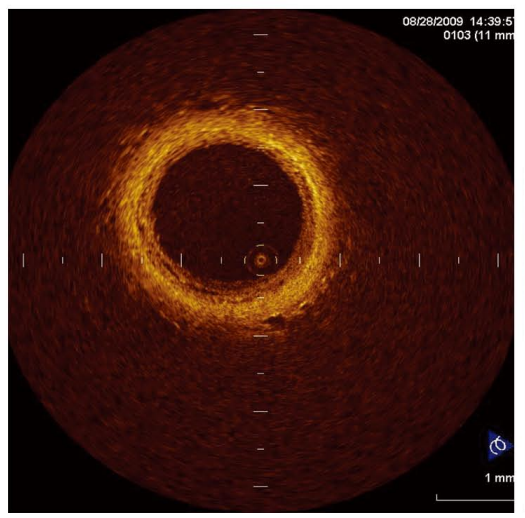

CTEPH

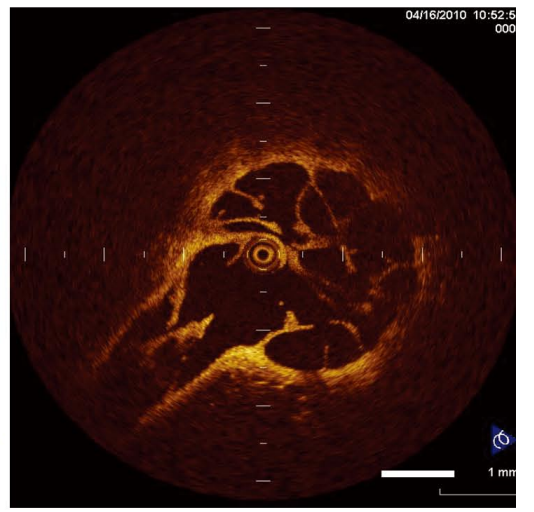

Figure 4. Representative optical coherence tomography (OCT) images of the pulmonary arteries from a control subject, a patient with pulmonary artery hypertension $(\mathrm{PAH})$ and one with chronic thromboembolic pulmonary hypertension (CTEPH). Mesh-like luminal flaps are frequently observed only in the pulmonary arteries of CTEPH patients. Scale bar, $1.0 \mathrm{~mm}$.

with PAH, it may not be the case with CTEPH. ${ }^{19}$ CTEPH is regarded as a consequence of PTE caused by venous thromboembolism; however, the occurrence of CTEPH in patients with acute PTE or deep venous thrombosis is rare. ${ }^{3}$ Thus, it is highly possible that the pathophysiology PAH and CTEPH is different.

\section{Recent Progress in the Diagnosis of PH}

\section{Right-Heart Catheterization}

Cardiac catheterization is important not only for diagnosing $\mathrm{PH}$ and excluding other causes but also to evaluate disease severity and prognosis assessment. Patients with PAH should have a normal PCWP, high PAP, high PVR, and normal or high right atrial pressure. When a wedge pressure cannot be obtained, direct measurement of LV end-diastolic pressure is advised (Figure 1). ${ }^{3}$

\section{Optical Coherence Tomography (OCT)}

OCT is an interferometer-based optical imaging modality that produces a 2-dimensional image of optical scattering from internal tissue microstructure with a high resolution of approximately $10-20 \mu \mathrm{m}$, which is 10 -fold higher than that of intravascular ultrasound. ${ }^{40-42} \mathrm{~A}$ recent report has demonstrated the usefulness of OCT as a novel diagnostic tool for differential diagnosis of distal type CTEPH from PAH. ${ }^{7}$ Pulmonary arteries larger than $1 \mathrm{~mm}$ had no obstruction in controls and PAH patients, although the media of the arteries appeared to be thickened in PAH patients compared with controls. ${ }^{7}$ In contrast, half of the CTEPH patients had occlusion of the pulmonary arteries, probably by thrombus, and more than half of them showed flaps in the lumen of the pulmonary arteries (Figure 4). ${ }^{7}$

Pathohistological studies have demonstrated that idiopathic PAH (IPAH) is associated with abnormal vascular structures, including medial and/or intimal hypertrophy, concentric and/or eccentric intimal fibrosis, obstruction in the arterial lumen, and aneurysmal dilatation in vessels smaller than $300 \mu \mathrm{m} .{ }^{19}$ In contrast, CTEPH results from the obstruction of pulmonary arteries by thrombus, mainly observed in large vessels. $^{43}$

\section{Computed Tomography (CT) Scan}

The role of chest CT scan has been established for both determining the presence and severity of PAH based on the diameter of the main pulmonary arteries and for diagnosing CTEPH. High-resolution CT scan can be reconstructed specifically to look at the lungs in detail (eg, the presence of PVOD) in each patient without the need for additional radiation. ${ }^{3,44}$ Typical CT scan images from PVOD patients show diffuse, poorly-defined centrilobular nodular opacities with associated septal line thickning. ${ }^{44}$

\section{New Treatment Algorithm of Pre-Capillary PAH}

The new treatment algorithm of PAH and connective tissue disease-associated PAH (CPAH) are shown in Figures $\mathbf{5}$ and 6 , respectively.

\section{Lifestyle Modification}

Heavy physical activity or isotonic exercise often causes right ventricular failure in patients with PAH/CTEPH.,45 Thus, low-level exercise in their daily life is recommended for those with PAH/CTEPH, because low-level physical training improves endothelial function, exercise capacity and quality of life, not only in those with coronary artery disease but also in those with PAH..$^{5,45}$ High altitude and infections should also be avoided because the former may produce hypoxic pulmonary vasoconstriction and the latter are fatal in some patients. ${ }^{5}$ In general, pregnancy is also not recommended in young women with $\mathrm{PAH}$, because of the high mortality..$^{3,5}$

\section{Prostacyclins}

Intravenous epoprostenol improves symptoms, 6-min-walk distance, hemodynamics and survival in patients with IPAH. ${ }^{46}$ It has been reported that intravenous epoprostenol improves survival rate in comparison with historical controls, with 1-, $2-, 3-$, and 5-year survival rates of $85 \%, 70 \%, 63 \%$, and $55 \%$, respectively, ${ }^{47}$ although this prostacyclin analog needs to be delivered by continuous intravenous infusion. Thus, it is important for patients with PAH/CTEPH to learn the techniques of sterile preparation of the drug, operation of an 


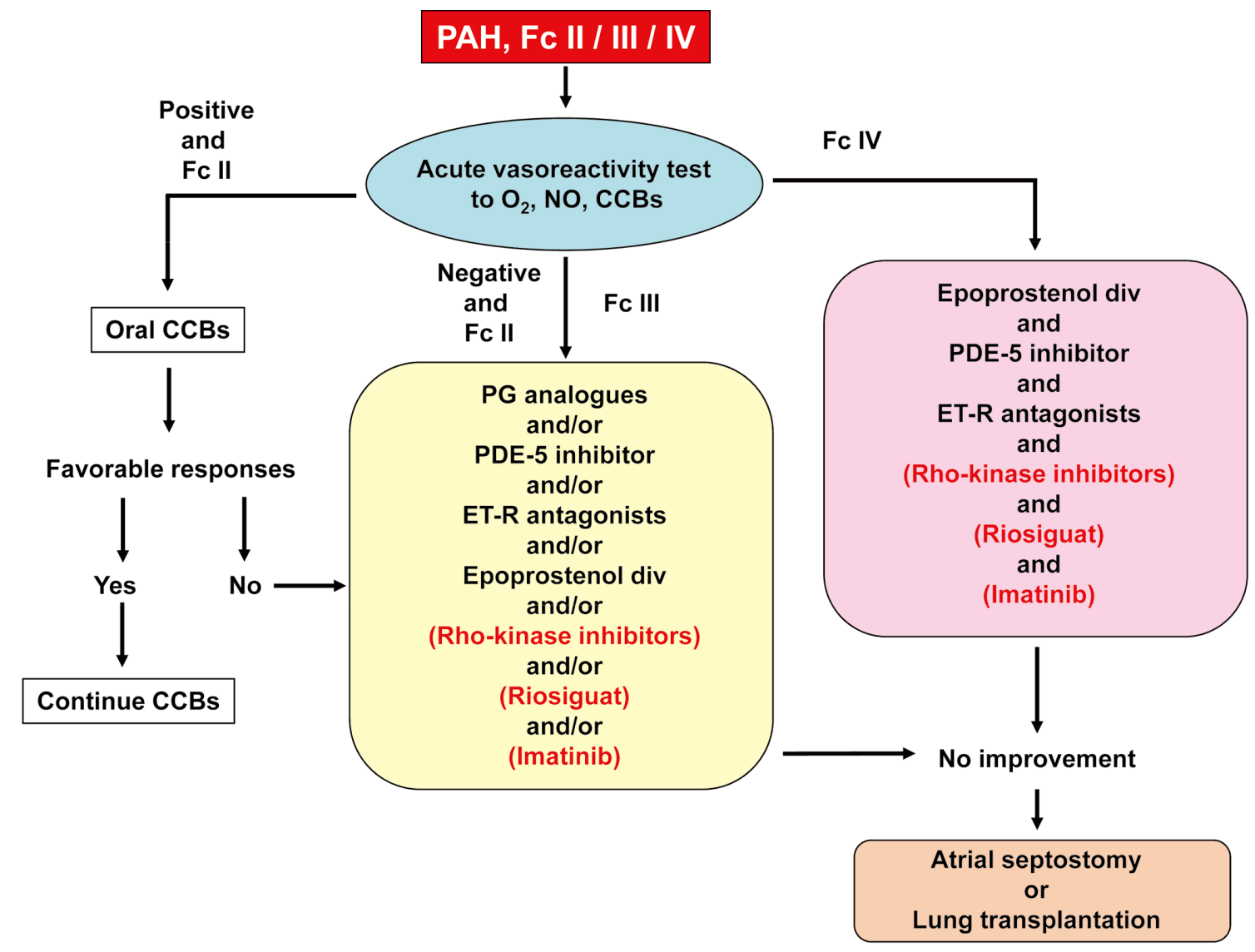

Figure 5. Treatment algorithm for pulmonary arterial hypertension. In FC II/III, combination therapy can be beneficial compared with monotherapy. In FC IV, maximum use of medicines may be required. CCBs, calcium-channel blockers; ETR, endothelin receptor; Fc, functional class; NO, nitric oxide; PAH, pulmonary arterial hypertension; PG, prostaglandin; PDE-5, phosphodiesterase-5.

ambulatory infusion pump and sterile handling of a central venous catheter. Epoprostenol therapy should be started during hospitalization and the starting dose of epoprostenol ranges between 0.5 and $1 \mathrm{ng} \cdot \mathrm{kg}^{-1} \cdot \mathrm{min}^{-1} \cdot{ }^{47}$ Its dose should be carefully increased in a step-wise manner on the basis of symptoms and side effects of the drug, because chronic overdose administration can cause high cardiac output failure. The side effects of intravenous epoprostenol include headache, jaw pain, flushing, nausea, diarrhea, skin rash, and musculoskeletal pain. ${ }^{8}$ In addition, infections and infusion interruptions can be life-threatening. Because of its considerable complexity, epoprostenol therapy should only be performed in centers with experience. Currently, 4 prostacyclin analogs are licensed for the treatment of PAH: epoprostenol, treprostinil, iloprost (in the USA and some European countries) and beraprost (in Japan and Korea). ${ }^{48}$ Prostacyclins are the treatment of choice in patients with severe $\mathrm{PAH}$, and their earlier use may also benefit PAH patients with mild-to-moderate severity. ${ }^{48}$ The advantages of prostacyclins are also noted in their integral role in combination therapy when a patient's condition has deteriorated following monotherapy with other agent (Figures 5, 6). ${ }^{6,48}$

\section{Phosphodiesterase-5 (PDE-5) Inhibitors}

Sildenafil, a potent and highly specific PDE-5 inhibitor, im- proved exercise capacity, symptoms and hemodynamics in patients with PAH in the Sildenafil Use in Pulmonary Hypertension (SUPER) trial. ${ }^{49}$ Side effects include headache, flushing, dyspepsia, and epistaxis. Tadalafil, which is also effective and well tolerated in patients with $\mathrm{PAH}$, has already been in clinical use (Figures 5,6). ${ }^{50}$

\section{Endothelin (ET) Receptor Antagonists}

Bosentan is the first drug in this class of ET antagonists that block both ETA and ETB receptors. Clinical trials have shown that treatment with bosentan increases exercise capacity and improves symptoms and pulmonary hemodynamics, not only in patients with PAH but also in those with Eisenmenger syndrome. ${ }^{51,52}$ The adverse effects of bosentan include headache, hypotension and liver dysfunction. ${ }^{53}$ Ambrisentan is a selective ETA receptor antagonist and its long-term use is also effective in improving symptoms, exercise capacity, pulmonary hemodynamics and time to clinical worsening in patients with PAH (Figures 5,6). ${ }^{3}$

\section{Immnosuppressive Therapy (Cyclophosphamide)}

It is widely accepted that immunological and inflammatory mechanisms contribute to the initiation and progression of PAH associated with connective tissue disease (CPAH), such as systemic sclerosis ( $\mathrm{SSc}$ ), systemic lupus erythematosus 


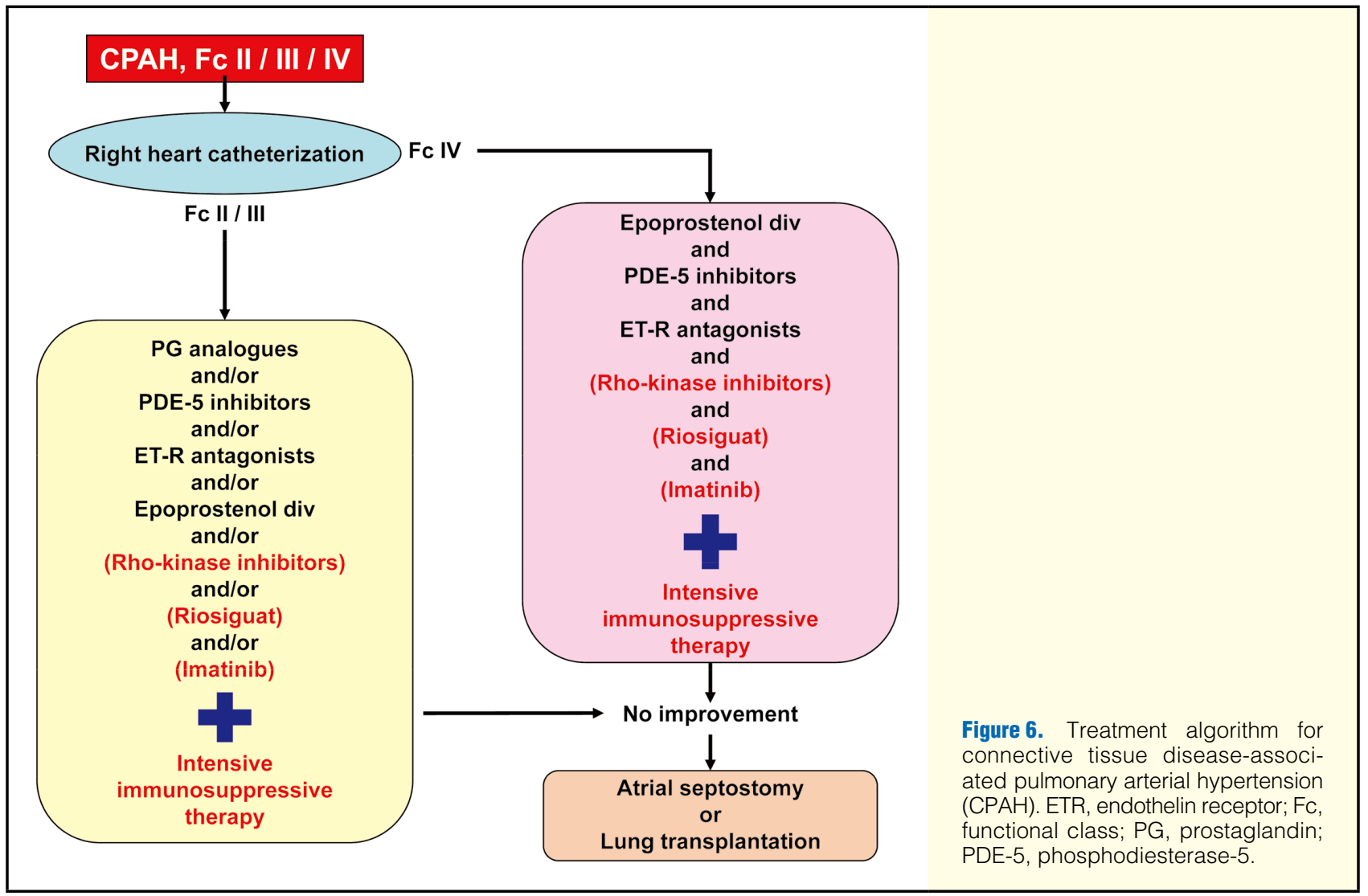

(SLE) and mixed connective tissue disease (MCTD)., ${ }^{4,25}$ Indeed, inflammatory cells (eg, macrophages and lymphocytes) have been detected in the plexiform lesions of the lung from CPAH patients. ${ }^{54,55}$ It has been recently reported that immunosuppressive therapy is effective in patients with SLE or MCTD, whereby half of those who responded to first-line immunosuppressive therapy alone showed improvement in symptoms, exercise tolerance and pulmonary hemodynamics. ${ }^{56,57} \mathrm{~A}$ recent study has demonstrated that intensive immunosuppressive therapy combined with cyclophosphamide and glucocorticosteroid on the top of conventional vasodilator therapy markedly improves pulmonary hemodynamics and long-term prognosis of patients with CPAH other than SSc-associated PAH (Figure 6) ${ }^{58}$ The effects of the intensive immunosuppressive therapy are evident when it is started immediately after the diagnosis of $\mathrm{CPAH} ;{ }^{57,58}$ however, future studies are required to identify the effects in a larger number of patients.

\section{New Agents}

Rho-Kinase Inhibitor Fasudil is a potent and selective inhibitor of Rho-kinase, ${ }^{20}$ with its inhibitory effect on Rhokinase being 100- and 1,000-fold more potent than on protein kinase $C$ and myosin light chain kinase, respectively. ${ }^{15}$ Long-term oral treatment with fasudil markedly ameliorated $\mathrm{PH}$ and pulmonary vascular lesions in a MCT-induced model in rats ${ }^{16}$ and a hypoxia-induced model in mice. ${ }^{18}$ Intravenous administration of fasudil also effectively reduces PVR in patients with PAH. ${ }^{17}$

Recent studies in a rat model of MCT-induced PH demonstrated that prostacyclin and its oral analog, beraprost sodium (BPS), do not have an inhibitory effect on Rho-kinase and that combination therapy with fasudil and BPS is more effective than each monotherapy for ameliorating PH. ${ }^{59,60}$ Indeed, it was demonstrated that IPAH patients with intravenous prostacyclin therapy showed favorable acute responses to fasudil. ${ }^{17,29}$ Thus, it is highly anticipated that combination therapy with prostacyclin and fasudil will have more beneficial effects in the treatment of PAH.

Bosentan, a dual inhibitor of ETA and ETB receptors, is another effective drug for the treatment of PAH in the clinical setting. ${ }^{53,61-63}$ However, not only ET but many other vasoactive substances (eg, serotonin, thrombin and plateletderived growth factor) are involved in the pathogenesis of $\mathrm{PAH}$, and importantly, all of them could activate the Rhokinase pathway. ${ }^{12,15,27,33}$ Because Rho-kinase inhibitors could inhibit signal transductions initiated by any of these vasoactive substances, it is possible that they exert more broadly beneficial effects than each single receptor antagonist. ${ }^{12,15,27,33}$ Recently, a clinical trial has been started to examine the midterm effect of the long-acting oral form of fasudil in patients with PAH in Japan (Figures 5,6).

Riociguat Riociguat is a novel, first-in-class oral drug that directly stimulates soluble guanylate cyclase, both independently of the endogenous vasodilator $\mathrm{NO}$ and in synergy with NO. ${ }^{64,65}$ Phase III clinical trials with riociguat are evaluating the long-term safety and clinical effectiveness of the agent in PAH and CTEPH patients (Figures 5, 6).$^{64-67}$

Imatinib Platelet-derived growth factor (PDGF) plays a critical role in the VSMC mitogen-activating signal transduction pathways associated with VSMC hyperplasia in PAH. ${ }^{68,69}$ Imatinib, a tyrosine kinase inhibitor of PDGF receptors, is expected to be a novel therapeutic agent for PAH, and is also under clinical trial (Figures 5,6). ${ }^{70}$ 


\section{New Treatment Algorithm of Post-Capillary PH Medications for Chronic HF}

No specific therapy has yet been developed for post-capillary $\mathrm{PH},{ }^{3}$ which is thus currently treated by drugs for the underlying diseases, including diuretics, nitrates, angiotensin-converting enzyme inhibitors, $\beta$-blockers and angiotensin-receptor blockers. ${ }^{71}$ Chronic trials with epoprostenol or bosentan in advanced HF have been terminated early because of an increased event rate in the investigational drug group compared with the conventional therapy group. ${ }^{72-74}$ Thus, novel therapeutic options need to be developed for post-capillary $\mathrm{PH}$.

\section{New Agents}

Rho-Kinase Inhibitor In animal models of diastolic HF (DHF), it has been demonstrated that activation of cardiac Rho-kinase is associated with the development of DHF and that cardiac Rho-kinase activity is highly correlated with myocardial stiffness of the LV in DHF. ${ }^{75}$ Furthermore, long-term inhibition of Rho-kinase with fasudil ameliorates DHF, independent of blood pressure-lowering effects, including the transition to decompensated HF, whereby amelioration of LV myocardial stiffness, but not that of LV relaxation properties, may be involved in the beneficial effects of fasudil..$^{75}$ Future studies are needed to examine the long-term effect of the oral form of fasudil in patients with $\mathrm{PH}$ caused by left heart disease.

Sildenafil Oral treatment with sildenafil exerts protective effects at the myocardial level in HF, targeting cardiac remodeling and $\mathrm{PH}$ due to left heart disease in animal models. ${ }^{76}$ The beneficial effects of sildenafil were also observed in patients with $\mathrm{HF}$ in a prospective, randomized, placebo-controlled study, where it improved functional capacity and clinical status, suggesting that LV diastolic function and cardiac geometry are additional targets of benefits with chronic PDE5 inhibition. ${ }^{77,78}$

Riociguat Phase III clinical trials of riociguat are evaluating its long-term safety and clinical effectiveness in $\mathrm{PH}$ caused by left heart disease. ${ }^{64-67}$

\section{New Treatment Algorithm of CTEPH}

\section{Pulmonary Artery Angioplasty}

Pulmonary thromboendoarterectomy is an established treatment for CTEPH, resulting in significant improvement in right ventricular hemodynamics and function. ${ }^{43}$ However, this surgical treatment is limited to central-type CTEPH and is not feasible for distal-type CTEPH. ${ }^{43,79}$ Although percutaneous transluminal pulmonary angioplasty (PTPA) was reported to improve pulmonary hemodynamics, symptom, and 6 -min walking distance, ${ }^{80}$ the procedure is limited by complications (eg, pulmonary hemorrhage and pulmonary edema) ${ }^{79,80}$ Indeed, distal-type CTEPH remains a serious condition with poor prognosis because of the lack of effective treatment. ${ }^{43}$ Accordingly, safer PTPA procedures have been recently developed with smaller sized balloons for less lobes per procedure, which may facilitate PTPA with less complications. ${ }^{81}$

\section{Future Perspectives}

$\mathrm{PH}$ remains a fatal disease, leading to right ventricular failure and premature death. Although significant research progress has been made on the pathogenesis, especially with regard to
Rho-kinase, the detailed mechanisms of the disorder remain to be elucidated. In clinical practice, significant progress has also been made for both diagnosis (eg, OCT) and treatment (eg, new ET blockers, Rho-kinase inhibitors, riociguat, and imatinib). The usefulness of these new drugs remains to be fully examined in future studies.

\section{Acknowledgments}

The authors' works presented in this article were supported in part by the grants-in-aid from the Japanese Ministry of Education, Culture, Sports, Science, and Technology, Tokyo, Japan, grants-in-aid for Scientific Research on Innovative Areas (Research in a Proposed Research Area), MEXT, Japan, and Tohoku University Global COE for Conquest of Signal Transduction Diseases with Network Medicine, Sendai, Japan.

\section{References}

1. Badesch DB, Champion HC, Sanchez MA, Hoeper MM, Loyd JE, Manes A, et al. Diagnosis and assessment of pulmonary arterial hypertension. J Am Coll Cardiol 2009; 54(Suppl): S55-S66.

2. Simonneau G, Robbins IM, Beghetti M, Channick RN, Delcroix M, Denton CP, et al. Updated clinical classification of pulmonary hypertension. J Am Coll Cardiol 2009; 54(Suppl): S43-S54.

3. Galie N, Hoeper MM, Humbert M, Torbicki A, Vachiery JL, Barbera JA, et al. Guidelines for the diagnosis and treatment of pulmonary hypertension. Eur Heart J 2009; 30: 2493-2537.

4. Humbert M, Morrell NW, Archer SL, Stenmark KR, MacLean MR, Lang IM, et al. Cellular and molecular pathobiology of pulmonary arterial hypertension. J Am Coll Cardiol 2004; 43(Suppl S): 13S24S.

5. Fukumoto Y, Tawara S, Shimokawa H. Recent progress in the treatment of pulmonary arterial hypertension: Expectation for rho-kinase inhibitors. Tohoku J Exp Med 2007; 211: 309-320.

6. Miura Y, Fukumoto Y, Sugimura K, Oikawa M, Nakano M, Tatebe $\mathrm{S}$, et al. Identification of new prognostic factors of pulmonary hypertension. Circ J 2010; 74: 1965-1971.

7. Tatebe S, Fukumoto Y, Sugimura K, Nakano M, Miyamichi S, Satoh K, et al. Optical coherence tomography as a novel diagnostic tool for distal type chronic thromboembolic pulmonary hypertension. Circ J 2010; 74: 1742-1744.

8. McLaughlin VV, McGoon MD. Pulmonary arterial hypertension. Circulation 2006; 114: 1417-1431.

9. Ishizaki T, Maekawa M, Fujisawa K, Okawa K, Iwamatsu A, Fujita A, et al. The small GTP-binding protein Rho binds to and activates a $160 \mathrm{kDa}$ Ser/Thr protein kinase homologous to myotonic dystrophy kinase. EMBO J 1996; 15: 1885-1893.

10. Amano M, Chihara K, Kimura K, Fukata Y, Nakamura N, Matsuura Y, et al. Formation of actin stress fibers and focal adhesions enhanced by Rho-kinase. Science 1997; 275: 1308-1311.

11. Narumiya $S$. The small GTPase Rho: Cellular functions and signal transduction. J Biochem 1996; 120: 215-228.

12. Shimokawa H, Takeshita A. Rho-kinase is an important therapeutic target in cardiovascular medicine. Arterioscler Thromb Vasc Biol 2005; 25: $1767-1775$.

13. Loirand G, Guerin P, Pacaud P. Rho kinases in cardiovascular physiology and pathophysiology. Circ Res 2006; 98: 322-334.

14. Shimokawa H. Cellular and molecular mechanisms of coronary artery spasm: Lessons from animal models. Jpn Circ J 2000; 64: $1-12$.

15. Shimokawa $\mathrm{H}$. Rho-kinase as a novel therapeutic target in treatment of cardiovascular diseases. J Cardiovasc Pharmacol 2002; 39: 319327.

16. Abe K, Shimokawa H, Morikawa K, Uwatoku T, Oi K, Matsumoto $\mathrm{Y}$, et al. Long-term treatment with a Rho-kinase inhibitor improves monocrotaline-induced fatal pulmonary hypertension in rats. Circ Res 2004; 94: 385-393.

17. Fukumoto Y, Matoba T, Ito A, Tanaka H, Kishi T, Hayashidani S, et al. Acute vasodilator effects of a Rho-kinase inhibitor, fasudil, in patients with severe pulmonary hypertension. Heart 2005; 91: 391-392.

18. Abe K, Tawara S, Oi K, Hizume T, Uwatoku T, Fukumoto Y, et al. Long-term inhibition of Rho-kinase ameliorates hypoxia-induced pulmonary hypertension in mice. J Cardiovasc Pharmacol 2006; 48: $280-285$.

19. Do.e Z, Fukumoto Y, Takaki A, Tawara S, Ohashi J, Nakano M, et al. Evidence for Rho-kinase activation in patients with pulmonary arterial hypertension. Circ J 2009; 73: 1731-1739.

20. Uehata M, Ishizaki T, Satoh H, Ono T, Kawahara T, Morishita T, 
et al. Calcium sensitization of smooth muscle mediated by a Rhoassociated protein kinase in hypertension. Nature 1997; 389: 990 994.

21. Somlyo AP, Somlyo AV. Signal transduction by G-proteins, rhokinase and protein phosphatase to smooth muscle and non-muscle myosin II. J Physiol 2000; 522: 177-185.

22. Masumoto A, Mohri M, Shimokawa H, Urakami L, Usui M, Takeshita A. Suppression of coronary artery spasm by the Rhokinase inhibitor fasudil in patients with vasospastic angina. Circulation 2002; 105: 1545-1547.

23. Mohri M, Shimokawa H, Hirakawa Y, Masumoto A, Takeshita A. Rho-kinase inhibition with intracoronary fasudil prevents myocardial ischemia in patients with coronary microvascular spasm. $J A m$ Coll Cardiol 2003; 41: 15-19.

24. Fujita H, Fukumoto Y, Saji K, Sugimura K, Demachi J, Nawata J, et al. Acute vasodilator effects of inhaled fasudil, a specific Rhokinase inhibitor, in patients with pulmonary arterial hypertension. Heart Vessels 2010; 25: 144-149.

25. Dorfmuller P, Perros F, Balabanian K, Humbert M. Inflammation in pulmonary arterial hypertension. Eur Respir J 2003; 22: 358 363

26. Hiroki J, Shimokawa H, Higashi M, Morikawa K, Kandabashi T, Kawamura N, et al. Inflammatory stimuli upregulate Rho-kinase in human coronary vascular smooth muscle cells. J Mol Cell Cardiol 2004; 37: $537-546$.

27. Liao JK, Seto M, Noma K. Rho kinase (ROCK) inhibitors. J Cardiovasc Pharmacol 2007; 50: $17-24$.

28. Oka M, Fagan KA, Jones PL, McMurtry IF. Therapeutic potential of RhoA/Rho kinase inhibitors in pulmonary hypertension. $\mathrm{Br} J$ Pharmacol 2008; 155: 444-454.

29. Ishikura K, Yamada N, Ito M, Ota S, Nakamura M, Isaka N, et al. Beneficial acute effects of Rho-kinase inhibitor in patients with pulmonary arterial hypertension. Circ J 2006; 70: 174-178.

30. Giaid A, Saleh D. Reduced expression of endothelial nitric oxide synthase in the lungs of patients with pulmonary hypertension. N Engl J Med 1995; 333: 214-221.

31. Xu W, Kaneko FT, Zheng S, Comhair SA, Janocha AJ, Goggans T, et al. Increased arginase II and decreased NO synthesis in endothelial cells of patients with pulmonary arterial hypertension. FASEB J 2004; 18: $1746-1748$.

32. Takemoto M, Sun J, Hiroki J, Shimokawa H, Liao JK. Rho-kinase mediates hypoxia-induced downregulation of endothelial nitric oxide synthase. Circulation 2002; 106: 57-62.

33. Shimokawa H, Rashid M. Rho-kinase inhibitors for cardiovascular medicine: Its rationale and current status. Trends Pharmacol Sci 2007; 28: 296-302.

34. Hoeper MM, Barbera JA, Channick RN, Hassoun PM, Lang IM, Manes A, et al. Diagnosis, assessment, and treatment of non-pulmonary arterial hypertension pulmonary hypertension. J Am Coll Cardiol 2009; 54(Suppl): S85-S96.

35. Delgado JF, Conde E, Sanchez V, Lopez-Rios F, Gomez-Sanchez MA, Escribano P, et al. Pulmonary vascular remodeling in pulmonary hypertension due to chronic heart failure. Eur J Heart Fail 2005; 7: $1011-1016$

36. Tatebe S, Fukumoto Y, Sugimura K, Satoh K, Miura Y, Miyamichi $\mathrm{S}$, et al. Clinical characteristics and prognostic impacts of post-capillary reactive pulmonary hypertension in patients with left heart disease. In: Scientific Sessions of the American Heart Association, Chicago, Nov. 15, 2010; 19237.

37. Mosquera I, Crespo-Leiro MG, Tabuyo T, Paniagua MJ, Fuente L, Bouzas B, et al. Pulmonary hypertension and right ventricular failure after heart transplantation: Usefulness of nitric oxide. Transplant Proc 2002; 34: 166-167.

38. Lang IM. Chronic thromboembolic pulmonary hypertension: Not so rare after all. $N$ Engl J Med 2004; 350: 2236-2238.

39. Bonderman D, Turecek PL, Jakowitsch J, Weltermann A, Adlbrecht C, Schneider B, et al. High prevalence of elevated clotting factor VIII in chronic thromboembolic pulmonary hypertension. Thromb Haemost 2003; 90: 372-376.

40. Tanimoto T, Imanishi T, Tanaka A, Yamano T, Kitabata H, Takarada $\mathrm{S}$, et al. Various types of plaque disruption in culprit coronary artery visualized by optical coherence tomography in a patient with unstable angina. Circ J 2009; 73: $187-189$

41. Sawada T, Shite J, Negi N, Shinke T, Tanino Y, Ogasawara D, et al. Factors that influence measurements and accurate evaluation of stent apposition by optical coherence tomography: Assessment using a phantom model. Circ J 2009; 73: $1841-1847$.

42. Ishigami K, Uemura S, Morikawa Y, Soeda T, Okayama S, Nishida $\mathrm{T}$, et al. Long-term follow-up of neointimal coverage of sirolimus-eluting stents: Evaluation with optical coherence tomography.
Circ J 2009; 73: 2300-2307.

43. Yoshimi S, Tanabe N, Masuda M, Sakao S, Uruma T, Shimizu H, et al. Survival and quality of life for patients with peripheral type chronic thromboembolic pulmonary hypertension. Circ J 2008; 72: 958-965.

44. Montani D, O'Callaghan DS, Savale L, Jais X, Yaici A, Maitre S, et al. Pulmonary veno-occlusive disease: Recent progress and current challenges. Respir Med 2010; 104(Suppl 1): S23-S32.

45. Mereles D, Ehlken N, Kreuscher S, Ghofrani S, Hoeper MM, Halank M, et al. Exercise and respiratory training improve exercise capacity and quality of life in patients with severe chronic pulmonary hypertension. Circulation 2006; 114: 1482-1489.

46. Barst RJ, Rubin LJ, Long WA, McGoon MD, Rich S, Badesch DB, et al. A comparison of continuous intravenous epoprostenol (prostacyclin) with conventional therapy for primary pulmonary hypertension. The Primary Pulmonary Hypertension Study Group. $N$ Engl J Med 1996; 334: 296-302.

47. Sitbon O, Humbert M, Nunes H, Parent F, Garcia G, Herve P, et al. Long-term intravenous epoprostenol infusion in primary pulmonary hypertension: Prognostic factors and survival. J Am Coll Cardiol 2002; 40: 780-788.

48. Vachiery JL. Prostacyclins in pulmonary arterial hypertension: The need for earlier therapy. Adv Ther 2011; 28: 251-269.

49. Galie N, Ghofrani HA, Torbicki A, Barst RJ, Rubin LJ, Badesch $\mathrm{D}$, et al. Sildenafil citrate therapy for pulmonary arterial hypertension. N Engl J Med 2005; 353: 2148-2157.

50. Barst RJ, Oudiz RJ, Beardsworth A, Brundage BH, Simonneau G, Ghofrani HA, et al. Tadalafil monotherapy and as add-on to background bosentan in patients with pulmonary arterial hypertension. J Heart Lung Transplant 2011; 30: 632-643.

51. Channick RN, Simonneau G, Sitbon O, Robbins IM, Frost A, Tapson VF, et al. Effects of the dual endothelin-receptor antagonist bosentan in patients with pulmonary hypertension: A randomised placebocontrolled study. Lancet 2001; 358: 1119-1123.

52. Galie N, Hinderliter AL, Torbicki A, Fourme T, Simonneau G, Pulido T, et al. Effects of the oral endothelin-receptor antagonist bosentan on echocardiographic and doppler measures in patients with pulmonary arterial hypertension. J Am Coll Cardiol 2003; 41: $1380-1386$

53. McLaughlin VV, Sitbon O, Badesch DB, Barst RJ, Black C, Galie $\mathrm{N}$, et al. Survival with first-line bosentan in patients with primary pulmonary hypertension. Eur Respir J 2005; 25: 244-249.

54. Dorfmuller P, Humbert M, Perros F, Sanchez O, Simonneau G, Muller KM, et al. Fibrous remodeling of the pulmonary venous system in pulmonary arterial hypertension associated with connective tissue diseases. Hum Pathol 2007; 38: 893-902.

55. Tuder RM, Groves B, Badesch DB, Voelkel NF. Exuberant endothelial cell growth and elements of inflammation are present in plexiform lesions of pulmonary hypertension. Am J Pathol 1994; 144: $275-285$

56. Sanchez O, Sitbon O, Jais X, Simonneau G, Humbert M. Immunosuppressive therapy in connective tissue diseases-associated pulmonary arterial hypertension. Chest 2006; 130: $182-189$.

57. Jais X, Launay D, Yaici A, Le Pavec J, Tcherakian C, Sitbon O, et al. Immunosuppressive therapy in lupus- and mixed connective tissue disease-associated pulmonary arterial hypertension: A retrospective analysis of twenty-three cases. Arthritis Rheum 2008; 58: $521-531$.

58. Miyamichi S, Fukumoto Y, Sugimura K, Satoh K, Nakano M, Miura Y, et al. Intensive immunosuppressive therapy improves pulmonary hemodynamics in patients with pulmonary arterial hypertension associated with connective tissue disease. In: Scientific Sessions of the American Heart Association, Chicago, Nov. 16, 2010; 15114.

59. Abe K, Morikawa K, Hizume T, Uwatoku T, Oi K, Seto M, et al. Prostacyclin does not inhibit Rho-kinase: An implication for the treatment of pulmonary hypertension. J Cardiovasc Pharmacol 2005; 45: $120-124$.

60. Tawara S, Fukumoto Y, Shimokawa H. Effects of combined therapy with a Rho-kinase inhibitor and prostacyclin on monocrotalineinduced pulmonary hypertension in rats. J Cardiovasc Pharmacol 2007; 50: $195-200$

61. Rubin LJ, Badesch DB, Barst RJ, Galie N, Black CM, Keogh A, et al. Bosentan therapy for pulmonary arterial hypertension. $N$ Engl J Med 2002; 346: 896-903.

62. Hiramoto Y, Shioyama W, Kuroda T, Masaki M, Sugiyama S, Okamoto K, et al. Effect of bosentan on plasma endothelin-1 concentration in patients with pulmonary arterial hypertension. Circ $J$ 2007; 71: $367-369$.

63. Akagi S, Matsubara H, Miyaji K, Ikeda E, Dan K, Tokunaga N, et 
al. Additional effects of bosentan in patients with idiopathic pulmonary arterial hypertension already treated with high-dose epoprostenol. Circ J 2008; 72: 1142-1146.

64. Ghofrani HA, Hoeper MM, Halank M, Meyer FJ, Staehler G, Behr $\mathrm{J}$, et al. Riociguat for chronic thromboembolic pulmonary hypertension and pulmonary arterial hypertension: A phase II study. Eur Respir J 2010; 36: 792-799.

65. Ghofrani HA, Voswinckel R, Gall H, Schermuly R, Weissmann N, Seeger W, et al. Riociguat for pulmonary hypertension. Future Cardiol 2010; 6: $155-166$.

66. Kim NH. Riociguat: An upcoming therapy in chronic thromboembolic pulmonary hypertension? Eur Respir Rev 2010; 19: 68-71.

67. Schermuly RT, Janssen W, Weissmann N, Stasch JP, Grimminger F, Ghofrani HA. Riociguat for the treatment of pulmonary hypertension. Expert Opin Invest Drugs 2011; 20: 567-576.

68. Heldin CH, Westermark B. Mechanism of action and in vivo role of platelet-derived growth factor. Physiol Rev 1999; 79: 1283-1316.

69. Balasubramaniam V, Tang JR, Maxey A, Plopper CG, Abman SH. Mild hypoxia impairs alveolarization in the endothelial nitric oxide synthase-deficient mouse. Am J Physiol 2003; 284: L964-L971.

70. Ghofrani HA, Morrell NW, Hoeper MM, Olschewski H, Peacock $\mathrm{AJ}$, Barst RJ, et al. Imatinib in pulmonary arterial hypertension patients with inadequate response to established therapy. Am J Respir Crit Care Med 2010; 182: 1171-1177.

71. Oudiz RJ. Pulmonary hypertension associated with left-sided heart disease. Clin Chest Med 2007; 28: 233-241.

72. Califf RM, Adams KF, McKenna WJ, Gheorghiade M, Uretsky BF, McNulty SE, et al. A randomized controlled trial of epoprostenol therapy for severe congestive heart failure: The Flolan International Randomized Survival Trial (FIRST). Am Heart J 1997; 134: $44-54$.

73. Kalra PR, Moon JC, Coats AJ. Do results of the ENABLE (Endothelin Antagonist Bosentan for Lowering Cardiac Events in Heart
Failure) study spell the end for non-selective endothelin antagonism in heart failure? Int J Cardiol 2002; 85: 195-197.

74. Packer M, McMurray J, Massie BM, Caspi A, Charlon V, CohenSolal A, et al. Clinical effects of endothelin receptor antagonism with bosentan in patients with severe chronic heart failure: Results of a pilot study. J Card Fail 2005; 11: 12-20.

75. Fukui S, Fukumoto Y, Suzuki J, Saji K, Nawata J, Tawara S, et al. Long-term inhibition of Rho-kinase ameliorates diastolic heart failure in hypertensive rats. J Cardiovasc Pharmacol 2008; 51: 317 326.

76. Yin J, Kukucka M, Hoffmann J, Sterner-Kock A, Burhenne J, Haefeli WE, et al. Sildenafil preserves lung endothelial function and prevents pulmonary vascular remodeling in a rat model of diastolic heart failure. Circ Heart Fail 2011; 4: 198-206.

77. Al-Hiti H, Melenovsky V, Syrovatka P, Kettner J, Malek I, Kautzner J. Sildenafil is more selective pulmonary vasodilator than prostaglandin $\mathrm{E}(1)$ in patients with pulmonary hypertension due to heart failure. Physiol Res 2010; 60: 303-308.

78. Guazzi M, Vicenzi M, Arena R, Guazzi MD. PDE5 inhibition with sildenafil improves left ventricular diastolic function, cardiac geometry, and clinical status in patients with stable systolic heart failure: Results of a 1-year, prospective, randomized, placebo-controlled study. Circ Heart Fail 2011; 4: 8-17.

79. Piazza G, Goldhaber SZ. Chronic thromboembolic pulmonary hypertension. N Engl J Med 2011; 364: 351-360.

80. Feinstein JA, Goldhaber SZ, Lock JE, Ferndandes SM, Landzberg MJ. Balloon pulmonary angioplasty for treatment of chronic thromboembolic pulmonary hypertension. Circulation 2001; 103: 10-13.

81. Sugimura K, Fukumoto Y, Satoh K, Miura Y, Tatebe S, Miyamichi $\mathrm{S}$, et al. Effects of percutaneous transluminal pulmonary angioplasty for distal-type chronic thromboembolic pulmonary hypertension. In: Eur Soc Cardiol, Paris, Aug. 29, 2011; 82669. 